\title{
A influência dos métodos de ensino-aprendizagem-treinamento no desenvolvimento da inteligência e criatividade tática em atletas de futsal
}

CDD. 20.ed. 796.07 796.331
Marcelo Vilhena SILVA* Pablo Juan GRECO**
*Universidade Federal

de Minas Gerais.

\begin{abstract}
Resumo
Este estudo analisou e descreveu os métodos de ensino-aprendizagem-treinamento (E-A-T) utilizados em três equipes de futsal, participantes do Campeonato Metropolitano de Belo Horizonte, relacionando os mesmos com o desenvolvimento do conhecimento tático processual divergente (criatividade) e convergente (inteligência). Para isso, foram filmadas em cada uma das três equipes, 18 sessões de treino e realizada posteriormente, a classificação desses treinos através do protocolo de SAAD (2002) e utilizado por MorelRA (2005). Já para a avaliação da evolução do conhecimento tático processual no interior de cada equipe foi realizada a bateria de testes KORA (MeMmeRT, 2002). Os resultados apontaram a utilização de três diferentes métodos de ensino-aprendizagem-treinamento: analítico; misto (analíticosituacional); e situacional. 0 grupo que utilizou o método analítico apresentou melhoras em relação à inteligência de jogo, mas não em relação à criatividade tática. Já os grupos que utilizaram os métodos misto e situacional apresentaram melhoras significativas tanto para o desenvolvimento da criatividade tática como da inteligência de jogo. Concluindo, os resultados indicam que as metodologias ativas, baseadas no desenvolvimento tático parecem ser mais interessantes para a construção do conhecimento tático-técnico e da criatividade ao mesmo tempo em que, podem evitar um desgastante processo de ensino da técnica e uma especialização precoce.
\end{abstract}

UNITERMOS: Futsal; Ensino-aprendizagem-treinamento; Conhecimento tático processual.

\section{Introdução}

Os jogos esportivos coletivos são modalidades que apresentam elementos comuns: um objeto, geralmente uma bola, movimentada com as mãos, pés ou bastões/raquetes; um terreno, onde acontece o jogo; uma meta, a ser atacada ou defendida; companheiros de equipe, que juntos cooperam buscando alcançar os objetivos do jogo; adversários, a serem superados; e regras a se respeitar (BAYER, 1986; GARGanta, 1998; Silva \& De Rose Junior, 2005).

Classificado como um jogo esportivo coletivo, o Futsal é uma modalidade de oposição/cooperação onde companheiros de equipe, em cooperação, lutam para alcançar seus objetivos ao mesmo tempo em que os adversários, em oposição, buscam impedir que esses objetivos sejam alcançados. É também, uma modalidade de invasão, uma vez que suas açôes acontecem em um espaço comum, com participação simultânea de atacantes e defensores em relação à bola, sem esperar a ação final do adversário. Assim, em determinados momentos, os jogadores se concentram em pequenos espaços o que, aliado ao fato do controle da bola ser feito com os pés, diferentemente de outros esportes, exige dos mesmos, além da capacidade de tomada de decisão, um elevado refinamento técnico no domínio da bola com os pés.

Dessa maneira, 10 atletas, divididos em duas equipes, participam do jogo de forma simultânea, variando suas açōes desde o momento em que se tem o controle (fase ofensiva) ou não da bola (fase defensiva), até alcançar os objetivos do jogo. Esses objetivos 
podem ser parciais (recuperar a posse de bola) ou finais (marcar o gol) (GARGANTA \& PINTO, 1998; REZER \& SAAD, 2005; SAAD, 2002; SAMPEDRO, 1993; SOUZA, 1999).

Enquanto uma equipe ataca, conservando a posse de bola e avançando no espaço em direção à meta contrária, a outra se defende, buscando recuperar a bola ao mesmo tempo em que, procura impedir o avanço do adversário, no próprio campo de jogo (SANTANa, 2006). Dessa forma, quando o atleta tem a posse da bola, procura jogar rapidamente, e não retêla excessivamente ao passo que, quando está sem a posse da mesma, precisa se movimentar constantemente a fim de recebê-la (no caso do ataque) ou se mobilizar para recuperá-la (no caso da defesa) (SANTANa, 2006). Sendo assim, ao estar com a posse da bola, o atleta precisará "Reconhecer os Espaços" de jogo e as melhores trajetórias para o envio da mesma aos seus companheiros (sem a posse da bola) que precisarão "Oferecer-se e Orientar-se" em relação a este jogador com a posse de bola, criando importantes linhas de passe. Vale destacar que, apesar das inúmeras possibilidades de ação do jogador com bola, o comportamento técnico-tático dos jogadores mais frequente em uma partida é realizado principalmente sem a posse de bola (SANTANA, 2006). Esse último autor verificou que atletas que permaneceram cerca de 30 minutos no jogo (tempo total dentro da quadra), não chegaram a manter a posse da bola, somada todas as suas ações, por dois minutos.

Por fim, ao caracterizar o futsal como um jogo esportivo coletivo de oposição/cooperação, jogado em um espaço comum com a participação simultânea de atacantes e defensores em relação à bola e de forte apelo à inteligência, verifica-se ser imprescindível que os atletas empreguem uma permanente atitude táticoestratégica (fortemente vinculada aos processos cognitivos relacionados à percepção, análise e tomada de decisão). Assim pode-se dizer que no Futsal, como em todos os jogos esportivos coletivos, a essência do rendimento é fundamentalmente tática (GARGANTA, 1998, 2000; Greco, 2003; Tavares, 1993; Tavares, GRECO \& GARGANTA, 2006).

Nesse contexto os jogos esportivos coletivos se caracterizam pela sucessão constante de situaçôes de jogo, nas quais o participante deve resolver problemas através de inúmeras tomadas de decisões, decisões estas que envolvem um conteúdo tático, e implicam em relacionar processos cognitivos com processos motores. Assim, quando um atleta realiza uma técnica específica da modalidade, por exemplo, um passe, ele toma uma decisão tática escolhendo essa ação motora como a mais adequada a resolver a situação de jogo e nesse caso o conhecimento tático declarativo e processual são interligados na busca dos objetivos do jogo.

Independente da modalidade é importante ressaltar que nos jogos esportivos coletivos a elaboração do processo de ensino-aprendizagem-treinamento deve ser formulado cuidadosamente, o que solicita do professor o conhecimento das diferentes alternativas metodológicas. Torna-se assim, fundamental oportunizar processos de ensino-aprendizagemtreinamento que promovam o desenvolvimento das potencialidades e competências dos alunos, respeitando suas diferenças individuais e promovendo um crescimento amplo e diversificado nas suas capacidades, fomentando sua integração e enriquecimento da sua personalidade. Por isso, nos últimos anos várias obras (BOMPA, 2003; CORRÊA, BENDA \& UGRINOWITSCH, 2006; De Rose Junior, 2006; GraçA \& Oliveira, 1998; Greco, 1995, 2002; Oliveira \& Paes, 2004; Santana, 2006; Tani, Bento \& Petersen, 2006) a respeito dos chamados jogos esportivos coletivos vêm sendo desenvolvidos. Paralelamente, vários estudos (Corrêa, Silva \& Paroli, 2004; Morales \& Greco, 2007; Moreira, 2005; NASCIMENTO \& Barbosa, 2000; Silva, 2007; Silva \& De Rose Junior, 2005) que tratam dos efeitos dos diferentes métodos de ensino, vêm proporcionando um maior conhecimento e compreensão sobre as alternativas pedagógicas e metodológicas a serem abordadas. Contudo, as discussões relativas a esse tema ainda se encontram muito em nível propositivo-ideológico.

Várias propostas e diferentes processos pedagógicos vêm sendo discutidos no intuito de facilitar a aprendizagem, o que tem possibilitado por sua vez, uma intervenção menos empírica e indutiva (SAAD, 2006).

Para SAAD (2006), a metodologia utilizada, no processo de ensino-aprendizagem-treinamento, deve apresentar uma aproximação com a ideia e com o sentido/significado do jogo como um todo, que por sua vez, promoverá segundo GRECO (2006), a melhoria das capacidades cognitivas subjacentes à tomada de decisão, particularmente do conhecimento declarativo e processual.

Mas o que é conhecimento declarativo e processual? $\mathrm{O}$ conhecimento declarativo pode ser definido como o conhecimento das informaçôes factuais (QUEIROGA, 2005) e se refere ao que pode ser expresso e narrado pelo atleta. $E$ aquilo que o atleta consegue explicar. São os fatos que podem ser declarados (GReCO, 2006). É um conhecimento que pode ser memorizado de forma a ser relembrado, posteriormente de forma verbal, exatamente como foi memorizado. Por fim, é o saber o que fazer (Eysenck \& KeANE, 1994). 
$\mathrm{O}$ conhecimento processual se refere à capacidade do atleta de executar tarefas complexas de forma automatizada, aparentemente sem o envolvimento de uma recordação consciente (FrENCH \& THOMAS, 1987; McPherson, 1999; Paula, 2000; Turner \& MartineK, 1995). Em síntese o conhecimento processual consiste no conhecimento de "como fazer as coisas" (QUEIROGA, 2005) e não pode segundo PaUla (2000), ser explicado e formulado explicitamente. Pode ser dividido em Conhecimento Divergente e Conhecimento Convergente. Para Sternberg (2000) o conhecimento convergente, relaciona-se com a inteligência, e pode ser caracterizado pelos processos que possibilitam ao indivíduo a escolha, entre múltiplas alternativas, daquela que é considerada como a mais adequada. Já o conhecimento divergente, relacionado com a criatividade, refere-se à produção de alternativas, com a formulação de ideias, na busca de soluçôes em detrimento às diversas situações que ocorrem na partida. É importante destacar que essas duas formas de conhecimento, convergente (inteligência) e divergente (criatividade), se relacionam e são utilizadas pelos atletas na solução das tarefas e problemas que defrontam no jogo, sendo possível mensurá-las através dos procedimentos validados nos testes KORA desenvolvidos por MEMMERT (2002).

$\mathrm{O}$ presente estudo analisou os métodos de ensinoaprendizagem-treinamento (E-A-T) empregados em três equipes de futsal participantes do Campeonato Metropolitano de Futsal de Belo Horizonte, e avaliou o nível de conhecimento tático processual (convergente e divergente, conforme MEMMERT, 2002) através da bateria de testes KORA dos atletas dessas equipes, analisando os efeitos dos métodos de ensinoaprendizagem-treinamento no desenvolvimento das capacidades táticas, mais especificamente nos parâmetros do conhecimento processual. Trabalhos de pesquisa visando compreender os efeitos das metodologias de ensino dos esportes no Brasil têm apresentado resultados coincidentes em relação às deficiências do método analítico no que se refere ao desenvolvimento da capacidade tática. $\mathrm{O}$ método Global, por sua vez, tem apresentado melhorias no rendimento tático (CorrêA, SILVA \& PAROLI, 2004). $\mathrm{O}$ método situacional também tem sido pesquisado em diferentes estudos (CorrêA, Silva \& Paroli, 2004; Morales \& Greco 2007; Moreira, 2005), mas ainda não existem resultados conclusivos em relação aos seus efeitos. Mesmo com as críticas, realizadas e apontadas em diferentes estudos com várias modalidades esportivas, principalmente no que diz respeito à pobreza na tomada de decisão e à forte dependência do aluno com o professor, o método analítico continua a ser um dos mais aplicados na iniciação esportiva (Greco, 2003; Greco \& Morales, 2007; Moreira, 2005; SAAD, 2002, 2006; SILVA, 2007).

\section{Materiais e métodos}

\section{Amostra}

Para a realização deste estudo foram observadas e analisadas três equipes de futsal da categoria mirim (crianças entre 12-13 anos), divididas em equipe M1, M2 e M3. Estas equipes disputaram o Campeonato Metropolitano de Futsal de Belo Horizonte 2007. Cada equipe era composta por 12 atletas cada totalizando assim, 36 atletas.

\section{Cuidados éticos}

Este estudo respeitou todas as normas estabelecidas pelo Conselho Nacional em Saúde sendo aprovado pelo Comitê de Ética da Pesquisa da UFMG, sendo aprovado mediante o parecer $\mathrm{n}^{\circ}$ ETIC. 0016/06 em 18 de maio de 2006.

\section{Coleta de dados}

Os testes foram aplicados em dois momentos distintos ( $1^{\mathrm{a}}$ e $3^{\mathrm{a}}$ etapas) e tiveram como objetivo avaliar a evolução do conhecimento tático processual (convergente e divergente) no interior de cada equipe.

Já as sessões de treino ( $2^{a}$ etapa), filmadas entre a realização do pré-teste e pós-teste, e analisadas posteriormente, tiveram o intuito de verificar quais os processos de ensino-aprendizagem-treinamento foram utilizados pelos treinadores de cada equipe. Nesta pesquisa foram analisadas 18 sessōes de treino de cada uma das três equipes, sendo categorizadas 54 sessōes. Cada sessão teve duração média de 90 minutos. 


\section{Instrumentos}

A bateria de testes KORA foi desenvolvida pelo grupo de estudos da Universidade de Heidelberg, na Alemanha, sob a orientação do prof. Dr. Roth, e validada por MEMmert (2002). São testes que permitem avaliar o conhecimento tático processual, nos parâmetros "Oferecer-se e Orientar-se" (OO) e "Reconhecer Espaços" (RE), sendo estes definidos, respectivamente, segundo KRÖGER e ROTH (2002), como "a qualidade do atleta de, a todo o instante, obter uma posição ótima para receber a bola" e; "a qualidade necessária ao atleta para que ele perceba as possibilidades de se chegar ao gol". Assim, no teste de se oferecer se orientar (OO) avalia-se o comportamento do jogador sem bola, e no teste de reconhecer espaços avalia-se o comportamento do jogador com bola. Cada teste foi enviado a três peritos que avaliaram o desempenho dos atletas e estabeleceram os pontos (de zero a 10 seguindo escala de Memmert, 2002) de acordo com as açôes táticas realizadas por cada um deles. Foi analisado o pensamento convergente e o pensamento divergente nas açôes táticas executadas. Os procedimentos estatísticos utilizados para a análise dos dados estão descritos no item Tratamento estatístico dos dados.

Teste de conhecimento tático processual KORA: oferecer-se e orientar-se (OO)

Os atletas receberam uma breve explicação a respeito do teste, seus objetivos e as instruçōes de como fazê-lo. A seguir foram divididos quatro grupos compostos por três atletas cada sendo que, duas destas equipes foram direcionadas para a área do teste (demarcada com fitas adesivas e cones). Cada uma delas experimentava o jogo durante um minuto e esclarecidas possíveis dúvidas, iniciava-se o teste. Após três minutos, a equipe atacante passava a defender e a defensora a atacar. Realizado o protocolo com estas duas equipes o procedimento era reiniciado com outras duas equipes (FIGURA 1).

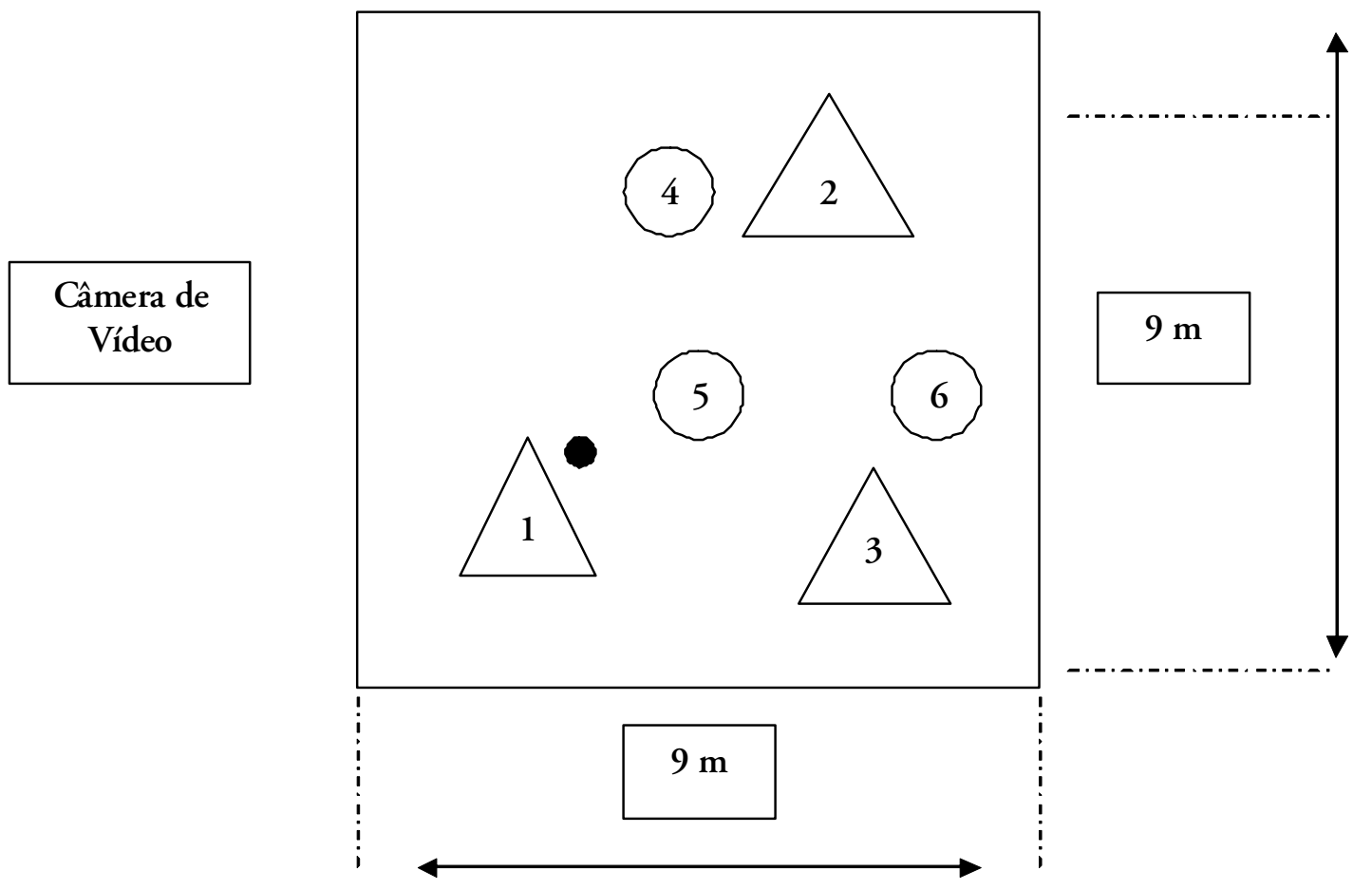

FIGURA 1 - Protocolo de avaliação do conhecimento tático utilizado para análise do parâmetro oferecer-se e orientar-se (Convergente e Divergente).

Teste de conhecimento tático processual KORA: reconhecer espaços (RE)

Os atletas receberam uma breve explicação a respeito do teste, seus objetivos e as instruçōes de como fazê-lo. Após o esclarecimento das dúvidas os atletas foram organizados em três grupos (composto por quatro componentes), sendo dois desses grupos, encaminhados para a área determinada para o teste. O grupo de posse de bola era divido em dois (dois atletas para cada lado) enquanto que a equipe responsável por interceptar os passes, com um dos integrantes retirado do teste, de forma aleatória por seu professor, se posicionava 
no setor central. Neste teste foram avaliados somente os jogadores que fizeram parte do "ataque" (equipe com posse de bola). Ao final de dois minutos, eram realizadas as trocas de função sendo que a equipe "atacante" passava para a "defesa" (com retirada de um dos integrantes) e a "defensora" (com o retorno do aluno retirado pelo professor) passava para o ataque. Após o término do procedimento com estas duas equipes, outras duas equipes iniciavam o teste (FIGURA 2).

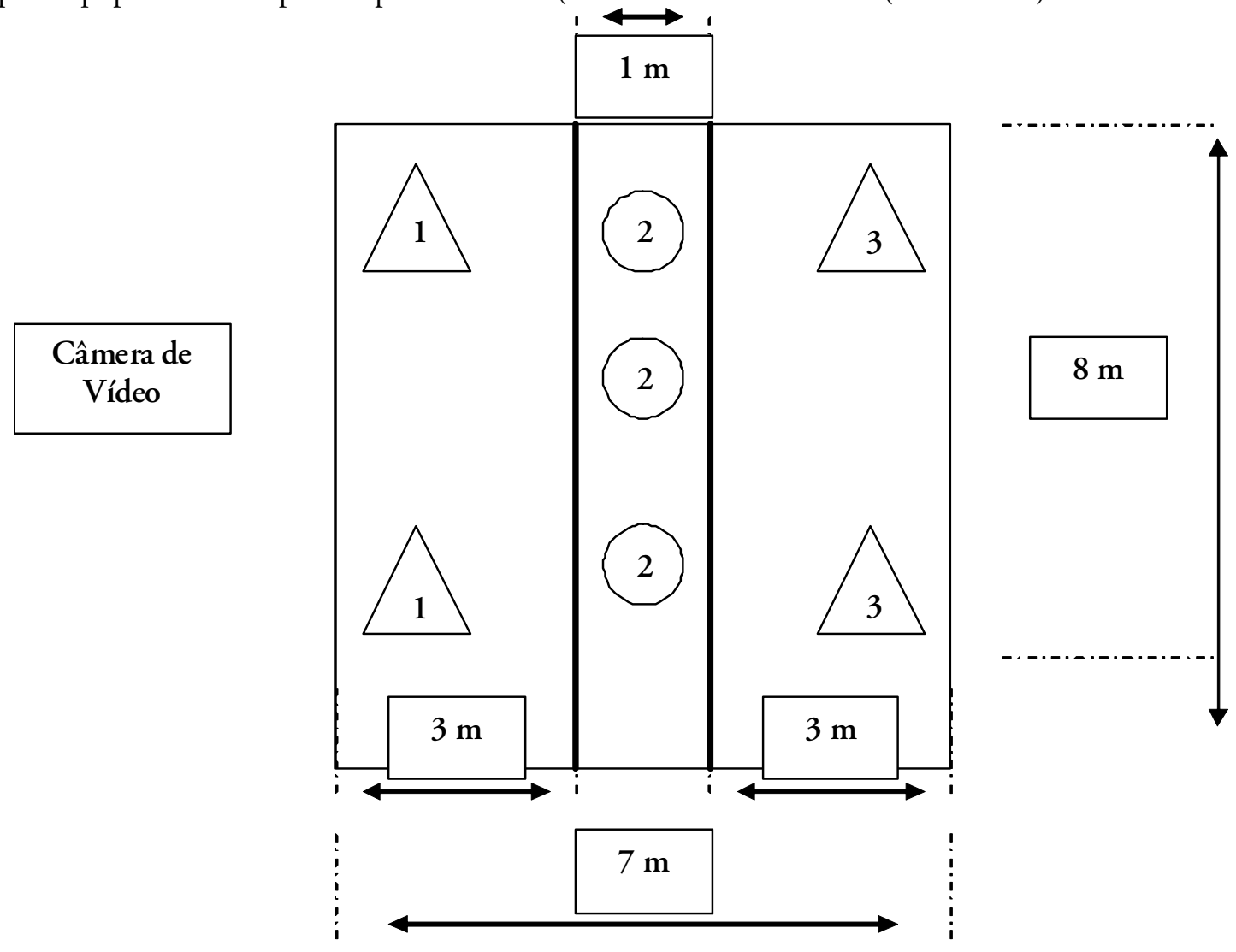

FIGURA 2 - Protocolo de avaliação do conhecimento tático utilizado para análise do parâmetro reconhecer espaços (Convergente e Divergente).

Observação sistemática e análise dos treinos (entre o pré-teste e o pós-teste)

Foram filmadas, em cada uma das três equipes participantes deste estudo, 18 sessóes de treino (cerca de seis semanas) e posteriormente, realizada a classificação desses treinos através do protocolo STEFANELLO (1999) adaptado para o Futsal por SAAD (2002) e também utilizado por Moreira (2005).

\section{Tratamento estatístico dos dados}

Para a análise dos valores obtidos, por cada um dos grupos, no pré-teste e pós-teste, foi utilizado o procedimento estatístico não paramétrico de Wilcoxon já que:

- O valor no teste de normalidade KolmogorovSmirnov, em cada um dos parâmetros táticos analisados (oferecer-se e orientar-se e, reconhecer espaços), foi inferior a 0,05 não apresentando, portanto, uma distribuição normal;
- A amostra de cada grupo foi menor do que 25 $(\mathrm{N}<25)$, ou seja, inferior à necessidade populacional para se aplicar análises paramétricas;

- Os dados coletados nas escalas de avaliação do teste KORA são do tipo ordinal;

- O teste de Wilcoxon permite analisar/comparar os resultados (escores) de uma mesma variável obtida em dois momentos distintos.

O nível de significância estabelecido foi de $\mathrm{p}<$ 0,05 para identificar diferenças significativas na variável de estudo.

Já para a observação da consistência interna, na avaliação dos peritos, foi realizada a análise fatorial (Alfa Cronbach). Vale ressaltar que foi estabelecida, nesse estudo, somente a fidedignidade nas avaliaçôes uma vez que, a bateria de testes KORA é um instrumento cuja validade, confiabilidade e objetividade já foram determinadas (MEMMERT, 2002).

$\mathrm{O}$ procedimento para estabelecer fidedignidade nas observações dos treinamentos esteve sustentado 
por sua vez, por meio da estabilidade e confiabilidade interna. Para se verificar a estabilidade foi realizada a técnica de teste/pré-teste onde um observador assistiu às fitas, correspondentes aos treinos de cada equipe, $\mathrm{e}$ registrou suas observaçôes conforme protocolo proposto por SAAD (2002). Após oito dias da primeira observação, realizou uma segunda análise, registrando novamente suas observações. Dessa forma, todas as sessōes de treinos foram analisadas duas vezes e em dois momentos distintos pelo mesmo observador.

Para se determinar a estabilidade desses dados, optou-se por calcular correlação de Spearman, levando em consideração que os valores encontrados são produtos da apreciação subjetiva e do nível do conhecimento que o observador possui da modalidade. Por fim, para a verificação da confiabilidade interna de avaliação, um segundo observador avaliou as fitas e registrou suas observações, conforme as categorias estabelecidas para o primeiro observador. Os dados do primeiro e do segundo observador foram utilizados para realizar análise fatorial (Alpha de Cronbach) e dessa forma obter consistência interna nas observaçōes, ou seja, confiabilidade.

Dessa forma, a fidedignidade no processo de categorização e estruturação dos treinamentos esteve garantida por meio da estabilidade e confiabilidade (estabilidade e confiabilidade intra e inter avaliadores). A estabilidade está determinada por índices de correlação significativos para um nível de significância de 0,05 e 0,01 . Ou seja, o valor do "r" calculado é maior do que o coeficiente crítico de correlação de Spearman (BArRos \& Reis, 2003; Thomas \& Nelson, 2002). Já a confiabilidade interna estaria determinada por valores no coeficiente Alpha de Cronbach acima 0,60 (Thomas \& Nelson, 2002).

Com base nas discussōes realizadas no decorrer desse estudo e nos diferentes métodos de ensinoaprendizagem-treinamento (E-A-T) serão discutidos, a partir de agora, os resultados encontrados por esta pesquisa.

\section{Apresentação e discussão dos resultados}

\section{Categorização e estruturação dos treinamentos}

Nesse estudo foram observados três diferentes métodos de ensino-aprendizagem-treinamento. $\mathrm{O}$ treinador da equipe M1 desenvolveu um processo de ensino-aprendizagem-treinamento com ênfase no desenvolvimento da técnica empregando o método analítico. $\mathrm{O}$ treinador da equipe M2 desenvolveu um processo de ensino-aprendizagem-treinamento misto (analítico-situacional), com uma ligeira ênfase no desenvolvimento da capacidade tática. Já o treinador da equipe M3, aplicou um processo de ensinoaprendizagem-treinamento centrado na capacidade tática com utilização do método situacional.

Para chegar a estas conclusões este estudo considerou e analisou três parâmetros de treinamento que serão explicados a seguir:

a) Segmento de treino - composto por: conversa com o treinador, aquecimento, treinamento técnico, treinamento tático, intervalo, coletivo, etc.;

b) Duração - tempo gasto para a realização de cada atividade e;

c) Condições da tarefa - classificadas em:
- Fundamento individual: execução de fundamentos técnicos isolados (voltada para o desenvolvimento técnico);

- Combinação de fundamentos: passe, condução, recepção, drible e chute (voltada para o desenvolvimento técnico);

- Complexo de jogo I: situações de jogo com enfoque tático, realizadas através da utilização das estruturas funcionais: $1 \times 1 ; 1 \times 1+1,2 \times 1,2 \times 2$; etc. (voltada para o desenvolvimento técnico-tático);

- Complexo de jogo II: situações de jogo com enfoque tático, representadas por pequenos jogos com ênfase em situações de jogo: contra-ataque, retorno defensivo, etc. (voltada para o desenvolvimento técnico-tático);

Jogo formal: atividade de competição governada por regras estabelecidas, onde os resultados são decididos pelas habilidades, estratégias (voltada para o desenvolvimento técnico).

Em relação ao segmento de treino, foram identificados sete segmentos: conversa com o treinador; treinamento físico; treinamento físico-técnico; treinamento técnico, treinamento técnico-tático, jogo (coletivo) e intervalo (FIGURA 3). 


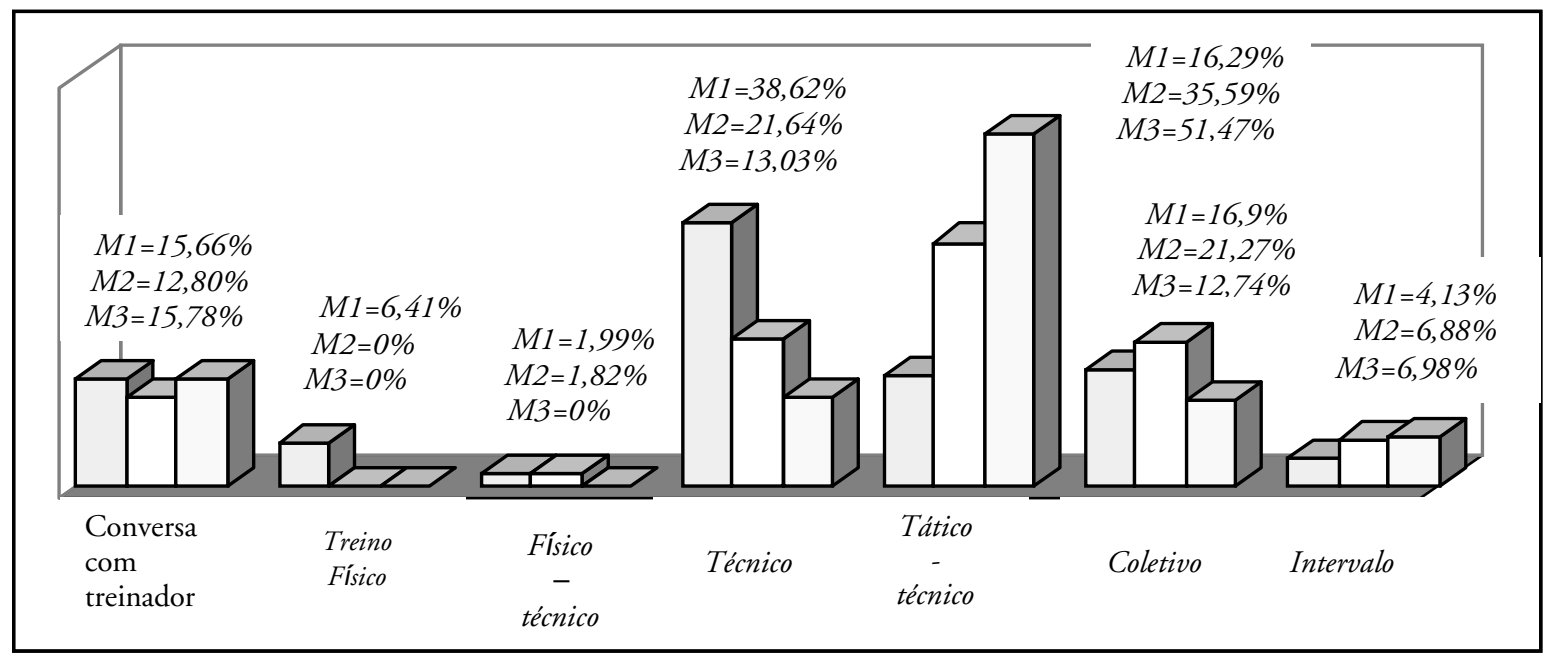

FIGURA 3 - Comparação da distribuição dos segmentos dos treinamentos das equipes M1 (método analítico), M2 (método misto) e M3 (método situacional) - Categoria mirim.

Vale ressaltar que a ênfase dada por cada uma das equipes a determinados segmentos do treino, se relaciona com o método de ensino-aprendizagem-treinamento empregado pelos seus respectivos treinadores.

Assim, percebe-se que a equipe M1 enfatizou o desenvolvimento da capacidade técnica por meio do método analítico. Já a equipe M2 apresentou uma maior diversificação dos conteúdos, baseando seu processo de ensino-aprendizagem-treinamento no método misto. Enquanto que a equipe M3, que aplicou um processo de ensino-aprendizagem-treinamento baseado no método situacional, enfatizou de forma significativa o segmento tático-técnico.

Em relação às condições das tarefas verificou-se que a equipe M1 utilizou, com maior frequência, atividades do parâmetro combinação de fundamentos $(41,41 \%)$, seguido de atividades relativas ao fundamento individual $(21,21 \%)$. Isso evidencia uma prioridade no desenvolvimento dos elementos técnicos (realizados de forma isolada e fora do contexto do jogo) em detrimento do componente informacional, perceptivo e de tomada de decisão, confirmando-se assim, o emprego do método analítico. $\mathrm{Na}$ equipe $\mathrm{M} 2$ dois parâmetros apresentaram a mesma distribuição de prioridade: a combinação de fundamentos (25\%) que enfatiza o desenvolvimento de habilidades técnicas e; o complexo de jogo II (25\%) que prioriza exercícios com situações semelhantes ao jogo. Esses dados indicam a utilização do método misto (analíticosituacional) com atividades divididas de forma relativamente equilibrada tanto entre conteúdos direcionados à melhoria da técnica quanto da tática. Por fim, a equipe M3, com proposta de ensinoaprendizagem-treinamento baseada no método situacional, apresentou uma maior freqüência no parâmetro complexo de jogo II $(35,65 \%)$ seguido do complexo de jogo I $(32,18 \%)$ demonstrando a preocupação do treinador pela apropriação inteligente da técnica em um contexto tático sob situações reais do jogo (Ver TABELA 1).

TABELA 1 - Comparação da distribuição das condições das tarefas realizadas nos treinamentos das equipes M1, M2, M3.

\begin{tabular}{lcccccc}
\hline & \multicolumn{2}{c}{ M1 } & \multicolumn{2}{c}{ M2 } & \multicolumn{2}{c}{ M3 } \\
\cline { 2 - 7 } & Incidência & Percentagem & Incidência & Percentagem Incidência Percentagem \\
\hline Fundamento individual & 21 & $21,21 \%$ & 13 & $13 \%$ & 7 & $6,09 \%$ \\
Combinação de fundamentos & 41 & $41,41 \%$ & 25 & $25 \%$ & 19 & $16,52 \%$ \\
Complexo de jogo I & 15 & $15,15 \%$ & 21 & $21 \%$ & 37 & $32,18 \%$ \\
Complexo de jogo II & 10 & $10,10 \%$ & 25 & $25 \%$ & 41 & $35,65 \%$ \\
Jogo & 12 & $12,13 \%$ & 16 & $16 \%$ & 11 & $9,56 \%$ \\
Total & 99 & $100 \%$ & 100 & $100 \%$ & 115 & $100 \%$ \\
\hline
\end{tabular}


Para se verificar a predominância no emprego dos diferentes métodos de E-A-T nas equipes foi observada a diferença na frequência e frequência percentual de utilização das categorias constitutivas do parâmetro condições das tarefas, por meio do cálculo do qui-quadrado $\left(\mathrm{X}^{2}\right)$. Portanto, que os parâmetros fundamento individual $\left(\mathrm{X}^{2}=7,21 \mathrm{p}<\right.$ $0,05)$, combinação de fundamentos $\left(X^{2}=9,12 p<\right.$ $0,05)$, complexo de jogo I $\left(\mathrm{X}^{2}=10,62 \mathrm{p}<0,05\right)$ e complexo de jogo II $\left(\mathrm{X}^{2}=18,96 \mathrm{p}<0,05\right)$, confirmaram diferenças existentes entre as três equipes.

\section{Nível de conhecimento tático processual}

Para a apresentação dos resultados provenientes da análise dos dados obtidos na aplicação do teste de conhecimento tático processual convergente/ divergente KORA OO - RE, nos pré-testes e póstestes, utilizou-se a soma total de pontos obtidos pela equipe M1, M2 e M3 sua moda e a mediana. A seguir foi utilizado o teste de Wilcoxon para verificar diferenças significativas entre os escores do pré e pós-testes das três equipes.

A equipe M1, com processo de ensinoaprendizagem-treinamento apoiado no método analítico, não apresentou melhoras significativas nos parâmetros OO divergente $(\mathrm{p}=0,66)$ e RE divergente $(\mathrm{p}=0,299)$, mas apresentou melhoras nos parâmetros OO convergente $(\mathrm{p}=0,001)$ e RE convergente $(\mathrm{p}=$ $0,030)$. Nos estudos realizados por Moreira (2005) e Morales e Greco (2007), que avaliaram o conhecimento processual convergente e divergente dos mesmos parâmetros desta pesquisa, o grupo que

\section{Considerações finais}

Este estudo analisou e descreveu os métodos de ensino-aprendizagem-treinamento utilizados no interior de três equipes de futsal pertencentes à categoria mirim (crianças de 12-13 anos). Além disso, procurou relacionar esses métodos com o desenvolvimento do conhecimento tático processual divergente (criatividade) e convergente (inteligência).

Foram observados três diferentes métodos de E-A-T. A equipe M1 desenvolveu um processo de E-A-T com ênfase no desenvolvimento da técnica o que caracterizou o emprego do denominado método analítico. A equipe M2 apresentou uma maior diversificação dos conteúdos, caracterizando o processo de E-A-T baseado no método misto (analítico-situacional). Já a desenvolveu a metodologia analítica apresentou melhoras no parâmetro $\mathrm{OO}$ tanto convergente quanto divergente, mas não no parâmetro RE convergente e divergente.Já equipe M2 com processo de ensinoaprendizagem-treinamento apoiado no método misto, apresentou melhoras em todos os parâmetros, $\mathrm{OO}(\mathrm{p}$ $=0,010$ divergente; $\mathrm{p}=0,031$ convergente) e $\mathrm{RE}$ ( $\mathrm{p}=$ 0,045 divergente; $\mathrm{p}=0,037$ convergente). Já nos estudos de Moreira (2005) e Morales e Greco (2007) nenhum destes parâmetros, seja convergente ou divergente apresentaram melhoras. Por fim, a equipe M3, com processo de ensino-aprendizagemtreinamento apoiado no método situacional, também apresentou melhoras em todos os parâmetros $(\mathrm{OO} p$ $=0,012$ divergente; $\mathrm{p}=0,036$ convergente; $\mathrm{e} \mathrm{RE} \mathrm{p}=$ 0,028 divergente; $\mathrm{p}=0,04$ convergente).

Os resultados encontrados pelas duas últimas equipes desta pesquisa sugerem que a ênfase no desenvolvimento da capacidade tática criativa, oportuniza a aquisição do conhecimento tático processual dos atletas de futsal participantes desta pesquisa.

A TABELA 2 apresenta os resultados encontrados por essas três equipes.

TABELA 2 - Resultados do prée pós-teste dos parâmetros oferecer-se e orientar-se (OO - Convergente e Divergente) e reconhecer espaços (RE Convergente e Divergente) das três equipes.

\begin{tabular}{lcccc}
\hline & OO & OO & RE & RE \\
Convergente & Divergente & Convergente & Divergente \\
\hline M1MA & $0,001^{*}$ & 0,066 & $0,030^{*}$ & 0,299 \\
M2MM & $0,031^{*}$ & $0,010^{*}$ & $0,037^{*}$ & $0,045^{*}$ \\
\hline
\end{tabular}

equipe M3 aplicou um processo de E-A-T baseado no método situacional.

As conclusōes relativas ao conhecimento tático processual, observadas nesse estudo serão descritas a seguir.

- Os processos voltados para o desenvolvimento técnico (equipe M1) não contribuíram para a melhora da criatividade tática (conhecimento processual divergente), mas apresentaram melhoras em relação à inteligência de jogo (conhecimento processual convergente).

- Os processos de ensino-aprendizagemtreinamento, que oferecem atividades voltadas tanto para a capacidade técnica quanto para a capacidade 
tática, através do emprego do método misto (equipe M2), parecem auxiliar tanto no desenvolvimento da inteligência de jogo (observado através da análise dos resultados dos parâmetros $\mathrm{OO}$ convergente e RE convergente) como da criatividade tática (observado através da análise dos resultados dos parâmetros $\mathrm{OO}$ divergente e RE divergente);

- Os processos de ensino-aprendizagemtreinamento, voltados para o desenvolvimento da tática influenciam positivamente o desenvolvimento tanto da criatividade tática como da inteligência de jogo. Neste estudo todos os parâmetros observados, OO convergente e divergente e RE convergente e divergente apresentaram melhoras significativas no interior da equipe com essa proposta (M3MS). Essas metodologias ativas oportunizam ao atleta uma construção do conhecimento tático-técnico ao mesmo tempo em que, evitam que os mesmos sejam condicionados a um desgastante processo de ensino da técnica e a uma especialização precoce, tirando assim, oportunidade de uma cultura esportiva apoiada na diversidade.

Por fim, é importante deixar claro que os resultados encontrados nesse estudo não podem ser generalizados a outras categorias, gêneros, e métodos de ensinoaprendizagem-treinamento uma vez que, dizem respeito especificamente às equipes analisadas.

\begin{abstract}
The effects of different teaching-learning-training strategies on development of tactical intelligence and creativity in futsal players

This study analyzed and described the teaching-learning-training methods employed in three futsal teams, relating them to the acquisition of procedural tactical knowledge in the manifestation of convergent (creativity) and divergent (intelligence) thoughts. Eighteen training sessions of each team were recorded and later on classified, by applying the protocol of SAAD (2002), used by MoreiRA (2005). The KORA tests (MEMMERT, 2002) were conducted in order to evaluate the acquisition of tactical knowledge within each team. The results indicate the predominant use of three different teaching-learning-training methods: analytical, mixed (analytical-situational) and situational. The analytical method contributed to improvements only in game intelligence, whereas the mixed method and the situational method provided improvements in both game intelligence and creativity. This suggests that the active methods, based on tactical development, are more favorable for the acquisition of tactical and technical skills and creativity, avoiding the monotonous process of teaching the specific game techniques by continuous repetition and early specialization.
\end{abstract}

UnITERMS: Futsal; Teaching-learning-training; Procedural tactical knowledge.

\title{
Referências
}

BARROS, M.V.G.; REIS, R.S. Análise de dados em atividade física e saúde: demonstrando a utilização do SPSS. Londrina: Midiograf, 2003.

BAYER, C. La enseñanza de los juegos deportivos colectivos. Barcelona: Hispano-Europea, 1986.

BOMPA, T.O. Treinamento de atletas de desporto coletivo. São Paulo: Phorte. 2003.

CORREAA, C.H.A.; BENDA, R.N.; UGRINOWITSCH, H. Processo ensino-aprendizagem no ensino do desporto. In: TANI, G.; BENTO, J.O.; PETERSEN, R.D.S. (Eds.). Pedagogia do desporto. Rio de Janeiro; Guanabara Koogan.2006. p.241-51.

CORREAA, C.H.A; SILVA, A.S.; PAROLI, R. Efeitos de diferentes métodos de ensino na aprendizagem do futebol de salão. Revista Motriz, Rio Claro, v.10, n.2, p.79-88, 2004.

DE ROSE JUNIOR, D. Modalidades esportivas coletivas. Rio de Janeiro: Guanabara Koogan, 2006.

EYSENCK, M.W.; KEANE, M.T. Psicologia cognitiva: um manual introdutório. Porto Alegre: Artes Médicas, 1994. FRENCH, K.E.; THOMAS, J. The relation of knowledge development to children's basketball performance. Journal of Sport Psychology, Champaign, v.9, p.15-32, 1987. 
GARGANTA, J. Para uma teoria dos jogos desportivos colectivos. In: GRAÇA, A.; OLIVEIRA, J. (Eds.). O ensino dos jogos desportivos. Porto: CEJD/FCDEF/Universidade do Porto, 1998. p.11-25.

O treino da táctica e da estratégia nos jogos desportivos. In: GARGANTA, I. (Ed.). Horizontes e órbitas no treino dos jogos desportivos. Porto: CEJD/FCDEF/Universidade do Porto, 2000. p51-61.

GARGANTA, J.; PINTO, J. O ensino do futebol. In: GRAÇA, A.; OLIVEIRA, J. (Eds.). O ensino dos jogos desportivos. Porto: CEJD/FCDEF/Universidade do Porto, 1998. p.95-136.

GRAÇA, A.; OLIVEIRA, J. O ensino do basquetebo. In: GRAÇA, A.; OLIVEIRA, J. (Eds.) O ensino dos jogos desportivos. Porto: CEJD/FCDEF/Universidade do Porto, 1998. p.61-94.

GRECO, P.J. O ensino do comportamento tático nos jogos esportivos coletivos: aplicação no handebol. 1995. $224 \mathrm{f}$. Tese (Doutorado em Educação: Psicologia Educacional) - Universidade Estadual de Campinas, Campinas, 1995.

O ensino-aprendizagem-treinamento dos esportes coletivos: uma análise inter e transdisciplinar. In: GARCIA, E.S.;

LEMOS, K.L.M. (Orgs.). Temas atuais VII em educação física e esportes. Belo Horizonte: Health, 2002. p.53-78.

. Processos Cognitivos: dependência e interação nos Jogos Esportivos Coletivos. In: GARCIA, E.; LEMOS, K.

(Orgs.). Temas atuais VIII em educação física e esportes. Belo Horizonte: Health, 2003. p.73-84.

. Iniciação esportiva universal e escola da bola: uma integração das duas propostas. In: GARCIA, E.; LEMOS, K.

(Orgs.). Temas atuais X em educação física e esportes. Belo Horizonte: Health, 2005. p.33-62.

Conhecimento tático-técnico: eixo pendular da ação tática (criativa) nos jogos esportivos coletivos. Revista

Brasileira de Educação Física e Esporte, São Paulo, v.20, p.210-2, 2006.

KRÖGER, C.; ROTH, K. Escola da bola: um abc para iniciantes nos jogos esportivos. São Paulo: Phorte, 2002.

McPHERSON, S.L. Tactical differences in problem representations and solutions in collegiate varsity and beginner female tennis players. Research Quarterly and Sport, Washington, v.7, n.4, p.369-84, 1999.

MEMMERT, D. Diagnostik Taktischer Leistungskomponenten: Spieltestsituationen und Konzeptorientierte Expertenratings. Tese (Doutorado) - Universidade de Heidelberg, Heidelberg, 2002.

MORALES, J.C.P.; GRECO, P.J. A influência de diferentes metodologias de ensino-aprendizagem-treinamento no basquetebol sobre o nível de conhecimento tático processual. Revista Brasileira de Educação Física e Esporte, São Paulo, v.21, p.291-99, 2007.

MOREIRA, V.J.P. A influencia de processos metodológicos de ensino-aprendizagem-treinamento (E-A-T) na aquisição do conhecimento tático no futsal. 2005. 180 f. Dissertação (Mestrado em Educação Física: Treinamento Esportivo) - Escola de Educação Física, Fisioterapia e Terapia Ocupacional da Universidade Federal de Minas Gerais, Belo Horizonte, 2005.

NASCIMENTO, J.V.; BARBOSA, G.B.. Estruturação das sessões técnico-táticas no voleibol infanto-juvenil e juvenil feminino: um estudo de caso. SIMPÓSIO NACIONAL DE EDUCAÇÃO FÍSICA, 19., 2000, Pelotas. Anais... Pelotas: [s.ed.\}, 2000, p.115-23.

OLIVEIRA, V.; PAES, R.R. A pedagogia da iniciação esportiva: um estudo sobre o ensino dos jogos desportivos coletivos. Lecturas, Educación Física y Deportes: Revista Digital, Buenos Aires, v.10, n.71, 2004. Disponível em: <http:// www.efdeportes.com/efd71/jogos.htm/>.

PAULA, P. Processo de validação de teste para avaliar a capacidade de decisão tática e o conhecimento declarativo no voleibol: situações de ataque de rede. 2000. 215 f. Dissertação (Mestrado em Educação física: Treinamento Esportivo) - Escola de Educação Física, Fisioterapia e Terapia Ocupacional da Universidade Federal de Minas Gerais. Belo Horizonte, 2000.

QUEIROGA, M.A. O conhecimento táctico-estratégico do distribuidor de alto nível: um estudo com distribuidores das selecções brasileiras de voleibol feminino e masculino. 183 f. Dissertação (Mestrado em Ciência do Desporto: Treino de Alto Rendimento). Universidade do Porto, FCDEF, Porto, 2005.

REZER, R.; SAAD, M.A. Futebol e futsal: possibilidades e limitaçōes da prática pedagógica em escolinhas. Chapecó; Argos, 2005.

SAAD, M.A. Estruturação das sessões de treinamento técnico-tático nos escalóes de formação do Futsal. $2002.101 \mathrm{f}$. Dissertação (Mestrado em Educação Física: Teoria e Prática Pedagógica em Educação Física) - Centro de Educação Física e Desporto, Universidade Federal de Santa Catarina. Florianópolis, 2002.

. Iniciação nos jogos esportivos coletivos. Lecturas, Educación Física y Deportes: Revista Digital, Buenos Aires, v.11, n.95, 2006. Disponível em: <http://www.efdeportes.com/efd95/inici.htm/>.

SAMPEDRO, J. Fútbol sala. Madri: Gymons editorial, 1993.

SANTANA, W.C. O modelo estratégico-tático do jogo de futsal na ótica de écnicos de sucesso e suas implicações no processo de ensino-aprendizagem-treinamento de jogadores jovens. 2006. Projeto de Qualificação (Doutorado em Educação Física) - Universidade Estadual de Campinas, 2006.

306 • Rev. bras. Educ. Fís. Esporte, São Paulo, v.23, n.3, p.297-307, jul./set. 2009 
SILVA, M.V. Processo de ensino-aprendizagem-treinamento (E-A-T) no futsal: influência no conhecimento tático processual. 2007. 208f. Dissertação (Mestrado em Educação Física: Treinamento Esportivo) - Escola de Educação Física, Fisioterapia e Terapia Ocupacional, Universidade Federal de Minas Gerais, Belo Horizonte, 2007.

SILVA, T.A.F.; DE ROSE JUNIOR, D. Iniciação nas modalidades esportivas coletivas: a importância da dimensão tática. Revista Mackenzie de Educação Física e Esporte, São Paulo, v.4. n.4, p.71-93, 2005.

SOUZA, P.R.C. Conhecimento tático no futsal: um estudo comparativo. 1999. 42 f. Monografia (Graduação em Educação Física) - Escola de Educação Física, Fisioterapia e Terapia Ocupacional da Universidade Federal de Minas Gerais. Belo Horizonte, 1999.

STEFANELLO, J.M.F. A participação da criança no desporto competitivo: uma tentativa de operacionalização e verificação empírica da proposta teórica de Urie Brofenbrenner. 1999. 232 f. (Tese de Doutorado em Educação Física) Faculdade de Ciências do Desporto e de Educação Física, Universidade de Coimbra. Coimbra, 1999.

STERNBERG, R.J. Psicologia cognitiva. Porto Alegre: Artmed, 2000.

TANI, G.; BENTO, J. O.; PETERSEN, R.D.S (Eds.). Pedagogia do desporto. Rio de Janeiro; Guanabara Koogan.2006. TAVARES, F. A capacidade de decisão táctica no jogador de basquetebol: estudo comparativo dos processos perceptivocognitivos em atletas seniores e cadetes. 1993. 151 f. Tese (Doutorado em Ciências do Desporto: Treinamento Desportivo) - Porto: FCDEF-UP. Porto, 1993.

TAVARES, F.; GRECO, P.; GARGANTA, J. Perceber, conhecer, decidir e agir nos jogos desportivos coletivos. In: TANI, G.; BENTO, J.O.; PETERSEN, R.D.S (Eds.). Pedagogia do desporto. Rio de Janeiro; Guanabara Koogan, 2006. p.284-98.

THOMAS, J.R.; NELSON, J.K. Métodos de pesquisa em atividade física. 3.ed. Porto Alegre: Artmed, 2002.

TURNER, A.; MARTINEK, T. Teaching for understanding: a model for improving decision making during game play. Quest, Champaign, v.44, p.44-63, 1995.

\begin{tabular}{|c|c|}
\hline ENDEREÇO & Recebido para publicação: 04/04/2008 \\
\hline Marcelo Vilhena Silva & 1a. Revisão: 27/04/2009 \\
\hline R. Sena Madureira, 404 - apto. 104 & 2a. Revisão: 18/o5/2009 \\
\hline $\begin{array}{r}\text { 31340-00o - Belo Horizonte - MG - BRASIL } \\
\text { e-mail: marcelo.vilhena@gmail.com }\end{array}$ & Aceito: 23/07/2009 \\
\hline
\end{tabular}

